\title{
Description of Ophthalmic Pharmaceutical and Device Start-Up Companies
}

\author{
R. Allan Sharpe ${ }^{a}$ Jennifer P. Austin ${ }^{b}$ Bonnie Kruft ${ }^{b}$ Lindsay A. Nelson ${ }^{b}$ \\ Jeanette A. Stewart ${ }^{b}$ William C. Stewart ${ }^{b}$ \\ a Medical University of South Carolina, Charleston, S.C., and bPRN Pharmaceutical Research Network, LLC, \\ Cheyenne, Wyo., USA
}

\section{Key Words}

Ophthalmic pharmaceuticals · Ophthalmic devices .

Start-up. Success · Product development

\begin{abstract}
Aims: To describe the number, type and location of ophthalmic companies and their associated product areas and indications. Methods: A retrospective, non-patient-based, observational review of ophthalmic pharmaceutical and device companies with a new product in development. Data was compiled by Internet searches. Results: We identified 190 companies currently developing ophthalmic products: 134 (71\%) were privately held and $56(29 \%)$ publicly held, while $136(72 \%)$ were in the United States and $53(28 \%)$ were outside the United States. There were 436 total products of which 338 (78\%) were pharmaceuticals and 98 (22\%) devices. With pharmaceuticals we identified 46 separate indications with age-related macular degeneration $(n=75)$, glaucoma $(n=52)$ and dry eye $(n=46)$ as most common; antivascular endothelial growth factor, hormone therapy and anti-inflammatory products were also common classes. With devices there were 30 indications with glaucoma $(n=26)$, age-related macular degeneration $(n=19)$ and dry eye $(n=$ 6) as most common; drug delivery, ocular implants and prostheses were less common classes. Conclusions: Ophthal-
\end{abstract}

mology as a specialty is benefited by a wide effort in new medicine and device development. However, a concentration of effort into relatively few indications suggests a potential lack of market analysis and possible difficulty for many companies in commercializing their product.

(C) 2015 S. Karger AG, Base

\section{Introduction}

The pharmaceutical and device industry has suffered from a reduction in the number of Food and Drug Administration (FDA)-approved products. For all new medicines (new molecular entities) the average has fallen from 40/year in 1990-1992, to 32/year in 2011-2013 [1, 2]. In ophthalmology the number of approved medicines has decreased from an average of 4/year in 1995-2000 to 2/year in 2009-2013 [3]. Likewise, the total number of premarket approvals per year for original devices has fallen from a recent high of 58 in 2001 to 21 in 2013 [4].

Several recent changes may have adversely influenced product development including: first, perceived higher regulatory standards required by the FDA; second, the difficulty in fostering new innovation; third, less available venture capital money, and last, venture capital firms, and major pharmaceutical companies, often acquiring new

\section{KARGER 125}

(c) 2015 S. Karger AG, Base

0030-3747/15/0541-0006\$39.50/0 
medications later in development to decrease investment risk [5-10].

Further, the historic business model for a medical start-up is even more difficult than for nonmedical startups, which often may produce revenue from an early product release. In contrast, a medical start-up must usually spend 4-10 years in product development before it might gain initial revenue. A recent study examined ophthalmic pharmaceutical start-ups and found only $20 \%$ were able to license their product after 4-15 years of existence [11]. Of approximately 10,000 medicines screened by start-ups, only 13 make it to preclinical studies and 1 makes it to market [12].

Despite these poor odds of success for start-ups, developing a new product within a larger company also may be difficult regardless of greater resources. The reasons for this are not fully known, but may be due to the higher cost of innovation and the administrative burden required to bring such products through a difficult multilayered committee-based corporate structure [13]. Consequently, successful ventures between start-ups and major pharmaceutical companies are often an important cooperation to effectively bring new ocular medicines to market [14-16].

The purpose of this study is to describe the number, type and location of ophthalmic companies and their associated product areas and indications.

\section{Materials and Methods}

The study design was a retrospective, non-patient-based, observational review of ophthalmic pharmaceutical and device companies with a new product in development. Due to the noninterventional, nonclinical participant study design Institutional Review Board/Ethics Committee approval was not required. This database was created in August 2010 and has been updated every 6 months, or as new companies were discovered. The last update was performed in June 2014.

Companies included in this analysis were developing an ophthalmic pharmaceutical or device and had the following information available online: company name; year founded; geographic location; public or private entity; therapeutic category; ophthalmic product name, and product class and phase of research. Companies that exited since 2010 (i.e., company acquired, bankruptcy, no longer in ophthalmology after merger, etc.) were excluded as well as companies without an English-language website and compounding pharmaceuticals were excluded.

Searches have been conducted by four authors (R.A.S., J.P.A., B.K., and L.A.N.). The metasearch engine www.Dogpile.com and search engine www.Google.com were used to identify applicable companies. The following search terms have been used: ophthalmology and pharmaceutical and device, device, technology, new product, start-up. Treatments for specific ophthalmic conditions were also searched including: glaucoma, age-related macular degeneration, dry eye, diabetic macular edema, cataract, conjuncti- vitis, uveitis, ocular pain/discomfort, diabetic retinopathy, presbyopia, retinal vein occlusion, and retinitis pigmentosa. The Association for Research in Vision and Ophthalmology 2011-2013 exhibitor lists were also reviewed. Company websites as well as www.ClinicalTrials.gov were used to verify details.

Each company was updated to validate and check for the most current information. The following information was collected as applicable for each company: company name; year founded; geographic location; public or private entity; therapeutic category; ophthalmic product name; development class, and phase of research. All information pertaining to the study was entered into an Excel spreadsheet. Quality assurance was performed on 100\% of entered data.

\section{Results}

Our search identified 190 companies developing ophthalmic products in January 2014. Of these, 134 (71\%) were privately held and $56(29 \%)$ publicly held. In the United States there were 136 (72\%) companies: 50 located in the West, 45 in the Northeast, 29 in the South and 11 in the Midwest and 1 in the Virgin Islands. The states that had the most companies were: California $(n=43)$, Massachusetts $(n=19)$, New York $(n=9)$, New Jersey $(n=7)$, Georgia $(n=7)$, and Maryland $(n=6)$. There were 54 (28\%) companies located outside the United States of which the most were in: Switzerland $(n=7)$, France $(n=$ $7)$, Israel $(n=6)$, and the United Kingdom $(n=6)$.

In the 190 companies identified there were 436 total products with 338 (78\%) being pharmaceuticals and 98 (22\%) treatment devices. With the pharmaceuticals there were 46 separate indications. Those with 10 or more products were: wet and dry age-related macular degeneration $(n=75)$, glaucoma $(n=52)$, dry eye $(n=46)$, diabetic macular edema $(n=30)$, uveitis $(n=20)$, conjunctivitis $(\mathrm{n}=18)$, and diabetic retinopathy $(\mathrm{n}=17)$. With the devices there were 30 separate indications. Those with more than 10 products were glaucoma $(n=26)$ and agerelated macular degeneration $(n=19)$.

For the pharmaceuticals the most common product classes broadly were: anti-vascular endothelial growth factor $(\mathrm{n}=25)$, hormone therapy $(\mathrm{n}=33)$, anti-inflammatory $(\mathrm{n}=35)$, intravitreal injections $(\mathrm{n}=13)$, monoclonal antibody $(n=21)$, gene therapy $(n=27)$, complement inhibitor $(\mathrm{n}=8)$, immunosuppressive agent $(\mathrm{n}=$ 10) and prostaglandin analog $(n=11)$. The most common product classes with the medical devices were: drug delivery $(n=19)$, ocular implants $(n=25)$, and prosthesis $(n=4)$. Table 1 shows the phase of research for each pharmaceutical product. 
Table 1. Number of current pharmaceutical products in each phase of pharmaceutical development

\begin{tabular}{lrc}
\hline Level & Count & Percent \\
\hline Preclinical & 145 & 33 \\
Phase I & 36 & 8 \\
Phase I/II & 26 & 6 \\
Phase II & 135 & 31 \\
Phase II/III & 4 & 1 \\
Phase III & 49 & 11 \\
Unknown & 40 & 9 \\
\hline Total & 436 & 100 \\
\hline
\end{tabular}

\section{Discussion}

These data showed several important features regarding the ophthalmic development community. First, there are a large number of companies, public and private, devoted to developing medicines and devices to help ophthalmic patients. The ophthalmic development community allows physicians the opportunity to utilize new products to better help our patients.

Nonetheless, developing new medications is particularly expensive if one considers that early start-ups need USD 1-2 million to begin operations, often up to USD 100 million to bring a medicine to license, and then bringing it to market may cost as much as USD 1 billion $[5,17]$. For devices premarket approval costs averaged USD 94 million, with USD 75 million spent on FDA-linked stages [18]. Consequently, for these companies the resources committed to the development of ophthalmic products specifically remain unknown, but must be quite large [4].

When an ophthalmic start-up company fails, as is typical in the pharmaceutical industry generally, there will be large amounts of time and money lost, risked by talented pharmaceutical and device professionals, ophthalmologists and investors. Despite appropriate reasons that cause some companies to dissolve, such as safety concerns or lack of efficacy, other reasons that might terminate projects may be lack of funding or development expertise, to the potential detriment of patients $[5,19]$.

While some reasons for the failure of start-ups were mentioned in the Introduction all the causes remain unknown. However, this report may further highlight several aspects of the difficulties in the start-up community bringing medicines to market.

This study showed that despite the existence of a large number of start-ups the greatest number of new medicines and devices were concentrated largely into four in- dications (age-related macular degeneration, glaucoma, dry eye and diabetic macular edema) often with overlapping and redundant mechanisms of action. In total, 346 (79\%) new medicines or devices were being developed within an indication with at least 10 other companies developing, at least broadly, the same class of medicine. This concentration of research efforts almost certainly guarantees the failure of many of the companies developing products within the same indication. In addition, the concentration of so many resources into few indications, despite disparate product classes in many cases, potentially suggests inadequate planning and market analysis before commencing business operations.

Our study also noted that the companies were geographically diverse, mostly located in a small number of states dispersed across the United States, with a fewer number being non-US-based, generally separated across Europe. This finding may indicate a further difficulty in product development as the identification of personnel and financial sources potentially may be made more difficult. Further, sharing of information and experience may not be easily accomplished between companies allowing for potential inefficiencies in the use of research monies and personnel effort. Of course, in modern development, where virtual models are common, many of the communication issues are mitigated through the use of web-based resources.

This study suggests that ophthalmology as a specialty is benefited by a wide effort in new medicine and device development. However, a concentration of effort into relatively few indications suggests a potential lack of market analysis and possible difficulty for many companies in commercializing their product.

Our study was limited to companies and data within the public realm accessible by the Internet. Other companies exist which are not yet in the public domain (internal data, PRN PharmaFarm). Further, often identifying the accurate class of medicine to which a new medicine belonged was often difficult by the public data. In addition, further research is needed to fully understand the complex needs of the ophthalmic start-up community to perhaps better assist the future successful commercialization of their products and advancements in fighting blindness.

\section{Disclosure Statement}

The authors report no conflict of interest. The authors alone are responsible for the content and writing of the article. This article received no financial support from any private or government funding source.
Sharpe/Austin/Kruft/Nelson/Stewart/ Stewart 


\section{References}

1 FDA drug and biologic approval reports. http://www.fda.gov/Drugs/DevelopmentApprovalProcess/HowDrugsareDevelopedandApproved/DrugandBiologicApprovalReports/default.htm.

2 Reichert JM: Trends in development and approval times for new therapeutics in the United States. Nat Rev Drug Discov 2003;2:695702 .

3 CenterWatch, FDA-Approved Drugs. http:// www.centerwatch.com/drug-information/ fda-approved-drugs/.

4 FDA impact on US medical technology innovation. http://www.advamed.org/NR/ rdonlyres/040E6C33-380B-4F6B-AB589AB1C0A7A3CF/0/makowerreportfinal.pdf.

5 Stewart WC, Stewart JA, Kruft B, Nelson LA: Challenges facing ophthalmic start-up companies in developing new devices or medicines. Acta Ophthalmol 2013;91:81-83.

6 Goodman CS, Gelijns AC: The changing environment for technological innovation in health care. Baxter Health Policy Rev 1996;2: 267-315.

7 How to finance a business with angel investors. http://www.forbes.com/2010/03/01/angel-investors-venture-capital-personal-finance-invest.html.
8 A funding fix for new businesses. http://www. forbes.com/2010/03/25/small-business-stimulus-entrepreneurs-finance-walter-buckley. html.

9 New exit strategies for venture capitalists. http://www.forbes.com/2010/03/05/venturecapital-ipo-entrepreneurs-finance-wharton. html.

10 Global recession knocks start-ups. http:// news.bbc.co.uk/2/hi/8455361.stm.

11 Stewart WC, Chaney PG, Stewart JA, Kruft B, Nelson LA: Qualitative factors underlying the successful investment in new ophthalmic pharmaceutical products in the United States. Acta Ophthalmol 2013;94:496-497.

12 The innovation gap in pharmaceutical drug discovery and new models for R\&D success. http://www.kellogg.northwestern.edu/biotech/faculty/articles/newrdmodel.pdf.

13 Peters TJ, Waterman RH: In Search of Excellence: Lessons from America's Best-Run Companies. New York, Harper \& Row, 1982.
4 Shafiee A, Bucolo C, Budzynski E, Ward KW, López FJ: In vivo ocular efficacy profile of mapracorat, a novel selective glucocorticoid receptor agonist, in rabbit models of ocular disease. Invest Ophthalmol Vis Sci 2011;52: 1422-1430.

15 Stewart WC, Crean CS, Zink RC, Brubaker K, Haque RM, Hwang DG: Pharmacokinetics of azithromycin and moxifloxacin in human conjunctiva and aqueous humor during and after the approved dosing regimens. Am J Ophthalmol 2010;150:744-751.

16 Baiula M, Spartà A, Bedini A, Carbonari G, Bucolo C, Ward KW, Zhang JZ, Govoni P, Spampinato S: Eosinophil as a cellular target of the ocular anti-allergic action of mapracorat, a novel selective glucocorticoid receptor agonist. Mol Vis 2011;17:3208-3223.

17 Collier R: Drug development cost estimates hard to swallow. CMAJ 2009;180:279-280.

18 Medical device makers spend millions to meet FDA rules, study finds. http://medcitynews. com $/ 2010 / 11 /$ medical-device-makersspend-millions-to-meet-fda-rules-studyfinds/.

19 Collins J: Good to Great: Why Some Companies Make the Leap... and Others Don't. New York, Harper Business, 2001. 